\title{
ANALISIS FAKTOR-FAKTOR YANG MEMENGARUHI PETANI DALAM MENGIKUTI ASURANSI USAHATANI PADI (AUTP) DI KABUPATEN SUKOHARJO
}

\author{
Lina Hidayatul Hamidah'), Joko Sutrisno'), Agustono') \\ 1)Fakultas Pertanian, Jurusan Agribisnis, Universitas Sebelas Maret, JI. Ir. Sutami No 36 A Kentingan \\ Surakarta, Telp (0271)637457, email: linahidayatul667@gmail.com
}

\begin{abstract}
Abstrak
Penelitian ini bertujuan untuk mengetahui pelaksanaan dan kinerja program Asuransi Usahatani Padi (AUTP) di Kabupaten Sukoharjo, menganalisis faktor-faktor yang mempengaruhi petani dalam mengikuti program AUTP, serta mengetahui peluang petani untuk mengikuti AUTP di Kabupaten Sukoharjo. Metode dasar penelitian yang digunakan adalah metode deskriptif dan analitis. Metode pengambilan lokasi secara purposive dan pengambilan sampel secara proportional random sampling dengan 60 responden. Data dianalisis menggunakan regresi logistik pada tingkat kepercayaan $95 \%(\alpha=0,05)$. Hasil penelitian menunjukkan bahwa mekanisme pelaksanaan program AUTP di Kabupaten Sukoharjo sudah baik sesuai panduan pelaksanaan dari pemerintah. Kinerja AUTP di Kabupaten Sukoharjo sudah baik, namun pengajuan klaim yang rumit dan klaim yang diberikan oleh pemerintah kepada petani masih perlu diperbaiki. Faktor-faktor yang memengaruhi petani dalam mengikuti program AUTP adalah faktor umur, penilaian anggota terhadap pengurus kelompok tani, mekanisme pelaksanaan, serta keyakinan klaim. Skenario yang memberikan peluang terbaik bagi petani mengikuti AUTP di Kabupaten Sukoharjo adalah skenario 3 dengan peluang 98,96\%.
\end{abstract}

Kata kunci: Asuransi, Keputusan, Padi, Risiko, Usahatani

\section{Abstract}

This study aims to determine the implementation and performance of the Rice Farming Insurance (AUTP) program in Sukoharjo Regency, to analyze the factors that influence farmers in participating the AUTP program, and determine the opportunities for farmers to participate in AUTP in Sukoharjo Regency. The basic research method used is descriptive and analytical methods. The method of taking location is purposive and the sampling is proportional random sampling with 60 respondents. The data were analyzed by using the logistic regression at $95 \%(\alpha=0.05)$ level showed. The results showed that the mechanism of implementating the AUTP program in Sukoharjo Regency was good. The implementation had followed the guidelines from the government. The AUTP's performance in Sukoharjo Regency is assessed well, but the submission of claims that still complicated and claims given by the government to farmers still needs to be improved. Factors that influence farmers in participating in the AUTP program are age, implementation mechanism, claim confidence, and the assessment of members of the farmer group management. The scenario that provides the best opportunity for farmers to participate AUTP in Sukoharjo Regency is scenario 3 with 98,96\% chance.

Keywords: Insurance, Decision, Rice, Risk, Farming

\section{PENDAHULUAN}

Indonesia adalah negara agraris yang bertumpu pada sektor pertanian, kehutanan, dan perikanan. Usahatani padi pada subsektor tanaman pangan memegang peranan penting sebagai pemasok kebutuhan konsumsi penduduk. Usahatani Padi untuk menunjang ketersediaan beras semakin terhambat. Luas lahan pertanian di Indonesia dan produktivitas padi mengalami penurunan. Beberapa risiko pertanian antara lain harga input pertanian dan output pertanian fluktuatif, perubahan iklim, perubahan kebijakan pertanian, meningkatnya kesulitan dalam menemukan pekerja yang berkualitas, dan meningkatnya kritik terhadap pertanian (Theuvsen, 2013). Kondisi tersebut 
diproyeksikan akan diperburuk oleh dampak perubahan iklim (Kawanishi et al., 2016).

Tanaman padi di Indonesia mengalami kekeringan dan kebanjiran pada tahun 2019 sebesar $10.716 \mathrm{Ha}$ dan $448.448 \mathrm{Ha}$. Luas kekeringan dan kebanjiran tanaman padi di Jawa Tengah tahun 2019 seluas $268.605 \mathrm{Ha}$ dan 28.505 Ha (Kementerian Pertanian, 2019). Luas kekeringan komoditas padi di Kabupaten Sukoharjo tahun 2019 mencapai $1.443 \mathrm{Ha}$ (Disnas Pertanian Kabupaten Sukoharjo, 2020).

Salah satu upaya untuk melindungi petani dari kegagalan panen dan untuk meminimalisir risiko pertanian yaitu dengan adanya kebijakan asuransi pertanian. Pemerintah dalam melindungi petani tercantum dalam UU No.19 Tahun 2013 tentang Perlindungan dan Pemberdayaan Petani, yang telah ditindaklanjuti dengan Penerbitan Peraturan Menteri Pertanian No. 40 Tahun 2015 tentang Fasilitasi Asuransi Pertanian. Pasal 19 ayat (1) dan (2) UU No. 19 Tahun 2013 menyatakan bahwa sesuai dengan kewenangannya, pemerintah pusat dan pemerintah daerah memfasilitasi setiap petani menjadi peserta asuransi. Salah satu fasilitas tersebut adalah bantuan pembayaran premi (Daniar, 2018).

Asuransi pertanian merupakan praktik manajemen risiko yang paling efektif dalam mengelola risiko produksi pertanian. Hanya sedikit petani yang mengikuti asuransi walaupun banyak yang sudah mengetahuinya. Petani yang tidak mengikuti asuransi memiliki alasan tertentu, antara lain ketidakmampuan membayar premi, kompensasi rendah, prosedur penyelesaian klaim rumit, perusahaan asuransi tidak terpercaya, lingkungan sekitar tidak ikut asuransi, tidak tahu tempat asuransi, serta adanya kemungkinan kerugian (Hazarika dan Sabina, 2018). Berdasarkan data dari Dinas Pertanian dan Perikanan Kabupaten Sukoharjo, petani padi di Kabupaten Sukoharjo berjumlah 48.126, namun hanya 9.935 petani yang mengikuti program Asuransi Usahatani Padi (AUTP). Berdasarkan data tersebut dapat dilihat bahwa petani yang mengikuti program AUTP di Kabupaten Sukoharjo sebesar 20,64\%. Asuransi Usahatani Padi di Kabupaten Sukoharjo tahun 2019 tidak memenuhi target. Target AUTP Kabupaten Sukoharjo tahun 2019 sebesar $4.000 \mathrm{Ha}$, namun hanya terealisasi sebesar 2.032,53 $\mathrm{Ha}$. Hal ini mendasari peneliti untuk melakukan penelitian mengenai Analisis Faktor-Faktor yang Memengaruhi Petani dalam Mengikuti Asuransi Usahatani Padi (AUTP) di Kabupaten Sukoharjo.

Tujuan dari penelitian ini adalah untuk mengetahui pelaksanaan dan kinerja program AUTP di Kabupaten Sukoharjo, menganalisis faktor-faktor yang memengaruhi petani dalam mengikuti program AUTP, serta mengetahui peluang petani untuk mengikuti AUTP di Kabupaten Sukoharjo.

\section{BAHAN DAN METODE}

Metode dasar yang digunakan dalam penelitian adalah metode deskriptif analitis. Penentuan lokasi penelitian menggunakan metode purposive sampling yaitu pemilihan lokasi penelitian yang dilakukan secara sengaja berdasarkan pada pertimbangan peneliti. Lokasi yang dijadikan sebagai tempat penelitian adalah Kabupaten Sukoharjo dengan pertimbangan bahwa Kabupaten Sukoharjo merupakan salah satu kabupaten yang menerapkan program Asuransi Usahatani Padi (AUTP). Kabupaten Sukoharjo dipilih dengan pertimbangan karena Kabupaten Sukoharjo memiliki tingkat risiko kebanjiran dan kekeringan yang cukup tinggi. Penentuan responden pada penelitian ini menggunakan teknik proportional random sampling. Sampel yang digunakan dalam penelitian dipecah ke dalam dua subsampel, yaitu subsampel petani yang ikut serta dalam AUTP dan subsampel petani yang tidak ikut serta dalam AUTP. Berdasarkan hal tersebut, maka diambil 60 sampel dengan pembagian sebanyak 30 petani yang mengikuti program AUTP dan 30 petani yang tidak mengikuti program AUTP. 
Agrisaintifika

Jurnal Ilmu-Ilmu Pertanian

Vol. 5, No. 1, 2021

Hamidah, et al. 2021

Metode analisis yang digunakan adalah metode deskriptif analitis dan analisis regresi logistik. Metode deskriptif analitis pada penelitian ini digunakan untuk mengetahui mekanisme pelaksanaan dan kinerja AUTP di Kabupaten Sukoharjo. Analisis regresi logistik pada penelitian ini digunakan untuk mengetahui pengaruh variabel-variabel yang diteliti terhadap minat petani dalam ikut serta program AUTP di Kabupaten Sukoharjo dan peluang petani mengikuti AUTP di Kabupaten Sukoharjo. Analisis regresi logistik biner digunakan untuk melihat pengaruh sejumlah variabel independen $x_{1}, x_{2}, \ldots \ldots, x_{k}$ terhadap variabel dependen $y$ yang berupa variabel response biner yang hanya mempunyai dua nilai atau juga untuk memprediksi nilai suatu variabel dependen $y$ (yang berupa variabel biner) berdasarkan nilai variabel-variabel independen.

$$
\begin{aligned}
Y= & \log \left(\frac{p}{1-p}\right) \\
= & \beta_{0}+\beta_{1} X_{1}+\beta_{2} X_{2}+\beta_{3} X_{3}+\beta_{4} X_{4}+\beta_{5} X_{5}+ \\
& \beta_{6} X_{6}+\beta_{7} D_{1}+\beta_{8} D_{2}+\beta_{9} D_{3}
\end{aligned}
$$

\section{HASIL DAN PEMBAHASAN}

\section{Mekanisme Pelaksanaan Program AUTP}

Pelaksanaan AUTP harus sesuai buku Pedoman Bantuan Premi Asuransi Usahatani Padi Tahun 2018. Peserta AUTP adalah petani pemilik atau penggarap yang melakukan usaha budidaya tanaman padi pada lahan paling luas dua hektar dan memiliki NIK. Lokasi Asuransi Usahatani Padi dilaksanakan di wilayah sentra produksi padi dan terletak dalam satu hamparan. AUTP memberikan jaminan atas kerusakan tanaman yang disebabkan oleh banjir, kekeringan, serta Organisme Pengganggu Tanaman (OPT) dengan kriteria umur padi sudah melewati 10 hari setelah tanam dan 30 hari setelah tebar. Intensitas kerusakan pengajuan klaim mencapai $\geq 75 \%$.

Premi yang dibayarkan sebesar $R p$ 36.000/Ha/MT dan klaim sebesar Rp 6.000.000/Ha/MT. Pembayaran klaim dilaksanakan 14 hari kerja sejak surat persetujuan pembayaran klaim. Petani membayar premi kepada asuransi pelaksana.
Apabila terdapat kerusakan, maka petani menyampaikan kepada PPL yang kemudian akan dilakukan perhitungan kerusakan.

Program AUTP di Kabupaten Sukoharjo sudah sesuai dengan pedoman yang diberikan oleh pemerintah. Terdapat dua pelaksanaan yang tidak sesuai dengan pedoman pemerintah. Pelaksanaan yang tidak sesuai dengan pedoman pemerintah adalah pembayaran premi kepada asuransi pelaksana dan pembayaran klaim dilaksanakan 14 hari kerja sejak surat persetujuan pembayaran klaim. Pembayaran premi dibayarkan petani/poktan kepada PPL untuk dihimpun kemudian dibayarkan kepada asuransi pelaksana atas nama petani atau kelompok tani. Pembayaran klaim yang seharusnya dilaksanakan 14 hari kerja sejak surat persetujuan pembayaran klaim tidak sesuai dengan kenyataan di lapangan dan sering terjadi keterlambatan pembayaran klaim.

\section{Kinerja Asuransi Usahatani Padi di Kabupaten Sukoharjo}

Kinerja Asuransi Usahatani Padi di Kabupaten Sukoharjo dapat diketahui berdasarkan penilaian petani mengenai premi dan klaim AUTP. Kinerja AUTP di Kabupaten Sukoharjo terlaksana dengan baik berdasarkan penilaian petani di Kabupaten Sukoharjo ditinjau dari sisi mekanisme pembayaran premi yang mudah, premi sesuai manfaat, biaya premi murah, kesanggupan petani membayar premi, subsidi yang mampu membantu petani, serta kesanggupan petani membayar premi tanpa subsidi.

Klaim asuransi adalah permintaan resmi kepada perusahaan asuransi untuk meminta pembayaran berdasarkan ketentuan perjanjian (Noviatri dan Sugeng, 2016). Klaim di Kabupaten Sukoharjo sesuai dengan risiko yang dialami petani, namun hanya 7 orang atau $23 \%$ petani AUTP dan 5 orang atau $17 \%$ petani non-AUTP yang menilai pengajuan klaim mudah. Artinya terdapat 23 petani AUTP dan 25 petani non-AUTP menilai pengajuan klaim di Kabupaten Sukoharjo rumit. 
Pengajuan klaim yang rumit dipengaruhi oleh tingginya risiko usahatani padi dan tidak adanya subsidi klaim dari pemerintah sehingga menyebabkan pihak asuransi lebih bijak dalam mencairkan dana klaim. Sebanyak 6 petani AUTP dan 2 petani non-AUTP menilai klaim menutup kerugian. Menurut sebagian besar responden, yaitu sebanyak 52 orang yang terdiri dari 24 petani AUTP dan 28 petani nonAUTP menilai bahwa klaim tidak mampu menutup kerugian, namun hanya mampu mengembalikan modal usahatani saja. Klaim di Kabupaten Sukoharjo sudah baik, namun terdapat dua hal yang perlu diperbaiki, yaitu pengajuan klaim yang rumit dan nilai klaim yang belum mampu menutup kerugian.

\section{Hasil Analisis Regresi Logistik Biner}

Faktor-faktor yang memengaruhi petani dalam mengikuti program AUTP antara lain faktor umur $\left(X_{1}\right)$, penilaian anggota terhadap pengurus kelompok tani $\left(\mathrm{X}_{6}\right)$, mekanisme pelaksanaan $\left(D_{2}\right)$, serta keyakinan klaim $\left(D_{3}\right)$. Variabel lainnya yaitu pendidikan $\left(X_{2}\right)$, luas lahan sawah yang dimiliki $\left(X_{3}\right)$, pendapatan $\left(X_{4}\right)$, jarak sawah ke sumber air $\left(X_{5}\right)$, dan premi $\left(D_{1}\right)$ tidak memiliki pengaruh nyata terhadap variabel dependen. Nilai signifikansi variabel umur yaitu $0,021<0,05$ sehingga umur berpengaruh secara signifikan terhadap keikursertaan petani dalam mengikuti AUTP. Variabel pendidikan memiliki signifikansi $0,394>0,05$ yang artinya variabel pendidikan tidak berpengaruh secara signifikan terhadap keputusan petani untuk mengikuti AUTP. Signifikansi luas lahan sawah yang dimiliki bernilai 0,203 $>0,05$ yang berarti variabel luas lahan yang dimiliki tidak berpengaruh secara signifikan terhadap keputusan petani dalam mengikuti AUTP. Nilai signifikansi variabel pendapatan yaitu 0,236 yang artinya variabel pendapatan tidak berpengaruh secara signifikan terhadap keputusan petani dalam mengambil program AUTP. Signifikansi jarak sawah ke sumber air bernilai 0,463 >0,05 yang artinya faktor jarak sawah ke sumber air tidak berpengaruh terhadap keputusan petani dalam mengambil program AUTP.
Koefisien variabel penilaian anggota terhadap pengurus kelompok tani sebesar $0,025<0,05$ yang artinya variabel penilaian anggota terhadap pengurus kelompok tani berpengaruh terhadap petani dalam mengikuti program AUTP. Signifikansi variabel premi bernilai $0,363>0,05$ yang artinya variabel premi tidak berpengaruh nyata terhadap tingkat partisipasi petani dalam mengikuti AUTP. Variabel mekanisme pelaksanaan memiliki signifikani 0,012 $<0,05$ yang artinya variabel mekanisme pelaksanaan berpengaruh terhadap keputusan petani dalam mengikuti program AUTP. Nilai signifikansi variabel keyakinan klaim adalah 0,016 $<0,05$ yang artinya variabel keyakinan klaim berpengaruh terhadap keputusan petani dalam mengikuti AUTP.

\section{Peluang Petani Mengikuti Asuransi Usahatani Padi di Kabupaten Sukoharjo}

Tujuan mengetahui peluang adalah untuk membantu membuat keputusan yang lebih tepat. Persamaan untuk peluang regresi logistik adalah sebagai berikut (Harlan, 2018):

$$
P\left(Y_{i}\right)=\frac{1}{1+e^{-(\beta 0+\beta 1 X 1+\ldots+\beta p X p)}}
$$

Terdapat delapan skenario yang digunakan untuk menghitung peluang dalam penelitian ini. Skenario 1 yaitu peluang petani mengikuti AUTP dengan kriteria petani berumur 57 tahun, pendidikan 8 tahun, luas lahan sawah yang dimiliki 0,49 $\mathrm{Ha}$, pendapatan 3,37 juta rupiah, jarak sawah ke sumber air 3 meter, nilai anggota terhadap pengurus kelompok tani 10, premi mahal, mekanisme pelaksanaan tidak rumit, dan petani yakin akan klaim. Skenario 2 adalah peluang petani mengikuti AUTP dengan kriteria petani berumur 57 tahun, pendidikan 8 tahun, luas lahan sawah yang dimiliki $0,49 \mathrm{Ha}$, pendapatan 3,37 juta rupiah, jarak sawah ke sumber air 3 meter, nilai anggota terhadap pengurus kelompok tani 10 , premi mahal, mekanisme pelaksanaan tidak rumit, dan petani tidak yakin akan klaim. Skenario 3 yaitu peluang petani mengikuti AUTP dengan kriteria petani berumur 57 tahun, pendidikan 8 tahun, 
luas lahan sawah yang dimiliki 0,49 $\mathrm{Ha}$, pendapatan 3,37 juta rupiah, jarak sawah ke sumber air 3 meter, nilai anggota terhadap pengurus kelompok tani 10, premi mahal, mekanisme pelaksanaan rumit, dan petani yakin akan klaim. Skenario 4 merupakan peluang petani mengikuti AUTP dengan kriteria petani berumur 57 tahun, pendidikan 8 tahun, luas lahan sawah yang dimiliki $0,49 \mathrm{Ha}$, pendapatan 3,37 juta rupiah, jarak sawah ke sumber air 3 meter, nilai anggota terhadap pengurus kelompok tani 10, premi mahal, mekanisme pelaksanaan rumit, dan petani tidak yakin akan klaim.

Skenario 5 adalah peluang petani mengikuti AUTP dengan kriteria petani berumur 57 tahun, pendidikan 8 tahun, luas lahan sawah yang dimiliki $0,49 \mathrm{Ha}$, pendapatan 3,37 juta rupiah, jarak sawah ke sumber air 3 meter, nilai anggota terhadap pengurus kelompok tani 10, premi murah, mekanisme pelaksanaan tidak rumit, dan petani yakin akan klaim. Skenario 6 yaitu peluang petani mengikuti AUTP dengan kriteria petani berumur 57 tahun, pendidikan 8 tahun, luas lahan sawah yang dimiliki $0,49 \mathrm{Ha}$, pendapatan 3,37 juta rupiah, jarak sawah ke sumber air 3 meter, nilai anggota terhadap pengurus kelompok tani 10, premi murah, mekanisme pelaksanaan tidak rumit, dan petani tidak yakin akan klaim. Skenario 7 merupakan peluang petani mengikuti AUTP dengan kriteria petani berumur 57 tahun, pendidikan 8 tahun, luas lahan sawah yang dimiliki $0,49 \mathrm{Ha}$, pendapatan 3,37 juta rupiah, jarak sawah ke sumber air 3 meter, nilai anggota terhadap pengurus kelompok tani 10, premi murah, mekanisme pelaksanaan rumit, dan petani yakin akan klaim. Skenario 8 yaitu peluang petani mengikuti AUTP dengan kriteria petani berumur 57 tahun, pendidikan 8 tahun, luas lahan sawah yang dimiliki $0,49 \mathrm{Ha}$, pendapatan 3,37 juta rupiah, jarak sawah ke sumber air 3 meter, nilai anggota terhadap pengurus kelompok tani 10 , premi murah, mekanisme pelaksanaan rumit, dan petani tidak yakin akan klaim.
Skenario yang memberikan peluang terbaik bagi petani mengikuti AUTP di Kabupaten Sukoharjo adalah skenario 3 dengan kriteria petani berumur 57 tahun, pendidikan 8 tahun, luas lahan sawah yang dimiliki 0,49 $\mathrm{Ha}$, pendapatan 3,37 juta rupiah, jarak sawah ke sumber air 3 meter, nilai anggota terhadap pengurus kelompok tani 10, premi mahal, mekanisme pelaksanaan rumit, dan petani yakin akan klaim. Skenario 3 sebesar $98,96 \%$ yang artinya peluang petani mengikuti AUTP di Kabupaten Sukoharjo lebih besar daripada peluang petani yang tidak mengikuti AUTP di Kabupaten Sukoharjo.

\section{SIMPULAN}

Mekanisme pelaksanaan program AUTP di Kabupaten Sukoharjo sudah baik sesuai panduan pelaksanaan dari pemerintah berdasarkan Buku Pedoman Bantuan Premi Asuransi Usahatani Padi Tahun 2018. Kinerja AUTP di Kabupaten Sukoharjo dinilai dari pengetahuan petani tentang AUTP dan pembayaran premi sudah baik, namun pengajuan klaim yang rumit dan klaim yang diberikan oleh pemerintah kepada petani masih perlu diperbaiki. Faktor-faktor yang memengaruhi petani dalam mengikuti AUTP adalah faktor umur $\left(X_{1}\right)$, penilaian anggota terhadap pengurus kelompok tani $\left(X_{6}\right)$, mekanisme pelaksanaan $\left(D_{2}\right)$, serta keyakinan klaim $\left(D_{3}\right)$. Skenario yang memberikan peluang terbaik bagi petani mengikuti AUTP di Kabupaten Sukoharjo adalah skenario 3 sebesar $98,96 \%$ dengan kriteria petani berumur 57 tahun, pendidikan 8 tahun, luas lahan sawah yang dimiliki $0,49 \mathrm{Ha}$, pendapatan 3,37 juta rupiah, jarak sawah ke sumber air 3 meter, nilai anggota terhadap pengurus kelompok tani 10, premi mahal, mekanisme pelaksanaan rumit, dan petani yakin akan klaim.

\section{DAFTAR PUSTAKA}

Daniar, G. 2018. Implementasi Asuransi Usaha Tani Padi Se-Eks karesidenan Pati dalam Mengatasi Gagal Panen (Studi 
Hamidah, et al. 2021

Kasus: Kabupaten Kudus, Kabupaten Pati dan Kabupaten Rembang). Journal of Politic and Government Studies 7(3): 1-16.

Dinas Pertanian Kabupaten Sukoharjo. 2020. Data Produksi, Luas Areal Panen dan Produktivitas Padi di Kabupaten Sukoharjo 2013-2017. Dinas Pertanian.

Harlan, J. 2018. Analisis Regresi Logistik. Jakarta: Gunadarma.

Hazarika C dan Sabina Y. 2018. Adaptability of Crop Insurance as a Risk Mitigation Mechanism by the Farmers of AssamAn Analysis of Modified National Agricultural Insurance Scheme (MNAIS). Journal of Advanced Agricultural Technologies 5(1): 58-62.

Kawanishi M, Guritno S, dan Yanuar F. 2016. Assessment of Farmer Demand for Crop Insurance: A Case Study in Indonesia. Journal of the Risk Research Society of Japan 26 (1): 19.

Kementerian Pertanian. 2019. Statistik Iklim, Organisme Pengganggu Tanaman, dan Dampak Perubahan Iklim 2016 2019. Jakarta: Kementerian Pertanian.

Noviatri L dan Sugeng. 2016. Analisis Faktor Penyebab Keterlambatan Penyerahan Klaim BPJS di RS Panti Nugroho. Jurnal Kesehatan Vokasional 1(1): 22-26.

Theuvsen, L. 2013. Risks and Risk Management in Agriculture. Scientific Journal 13(4): 162-174. 
Agrisaintifika

Jurnal Ilmu-Ilmu Pertanian

Vol. 5, No. 1, 2021

Hamidah, et al. 2021

\section{LAMPIRAN}

Tabel 1. Penilaian Petani Mengenai Premi AUTP

\begin{tabular}{llcccc}
\hline \multirow{2}{*}{ No } & \multicolumn{1}{c}{ Keterangan } & \multicolumn{2}{c}{ Petani AUTP } & \multicolumn{2}{c}{ Petani Non-AUTP } \\
\cline { 3 - 5 } & & $\begin{array}{c}\text { Jumlah } \\
\text { (Orang) }\end{array}$ & $\begin{array}{c}\text { Persentase } \\
(\%)\end{array}$ & $\begin{array}{c}\text { Jumlah } \\
\text { (Orang) }\end{array}$ & $\begin{array}{c}\text { Persentase } \\
(\%)\end{array}$ \\
\hline 1 & Mekanisme Pembayaran Mudah & 30 & 100 & 11 & 37 \\
2 & Premi Sesuai Manfaat & 29 & 97 & 18 & 60 \\
3 & Biaya Premi Murah & 29 & 97 & 25 & 83 \\
4 & Premi Sesuai Kesanggupan Membayar & 30 & 100 & 26 & 87 \\
5 & Subsidi Membantu Petani & 30 & 100 & 26 & 87 \\
6 & Kesanggupan Membayar Tanpa Subsidi & 21 & 70 & 27 & 90 \\
\hline
\end{tabular}

Sumber: Analisis Data Primer, 2020

Tabel 2. Penilaian Petani Mengenai Klaim AUTP

\begin{tabular}{llcccc}
\hline \multirow{2}{*}{ No } & Keterangan & \multicolumn{2}{c}{ Petani AUTP } & \multicolumn{2}{c}{ Petani Non-AUTP } \\
\cline { 3 - 6 } & & $\begin{array}{c}\text { Jumlah } \\
\text { (Orang) }\end{array}$ & $\begin{array}{c}\text { Persentase } \\
(\%)\end{array}$ & $\begin{array}{c}\text { Jumlah } \\
\text { (Orang) }\end{array}$ & $\begin{array}{c}\text { Persentase } \\
(\%)\end{array}$ \\
\hline 1 & Klaim Sesuai Risiko & 30 & 100 & 26 & 87 \\
2 & Pengajuan Klaim Mudah & 7 & 23 & 5 & 17 \\
3 & Setuju Syarat Klaim & 16 & 53 & 19 & 63 \\
4 & Klaim Menutup Kerugian & 6 & 20 & 2 & 7 \\
5 & Keyakinan Klaim & 28 & 93 & 25 & 83 \\
\hline
\end{tabular}

Sumber: Analisis Data Primer, 2020

Tabel 3. Hasil Regresi Logistik Faktor yang Memengaruhi Petani Mengikuti AUTP

\begin{tabular}{lcccc}
\hline \multicolumn{1}{c}{ Variabel } & Koefisien & $\begin{array}{c}\text { Standar } \\
\text { Defiasi }\end{array}$ & Signifikansi & $\begin{array}{c}\text { Odds } \\
\text { Ratio }\end{array}$ \\
\hline Umur $\left(\mathrm{X}_{1}\right)$ &, 177 &, 076 &, 021 & 1,193 \\
Pendidikan $\left(\mathrm{X}_{2}\right)$ &, 212 &, 249 &, 394 & 1,237 \\
Luas Lahan Sawah yang Dimiliki &, 001 &, 001 &, 203 & 1,001 \\
$\left(\mathrm{X}_{3}\right)$ &, 000 &, 000 &, 236 & 1,000 \\
Pendapatan $\left(\mathrm{X}_{4}\right)$ &, 341 &, 465 &, 463 & 1,407 \\
Jarak Sawah ke Sumber Air $\left(\mathrm{X}_{5}\right)$ & $-1,359$ &, 606 &, 025 &, 257 \\
Penilaian Anggota Terhadap & $-1,986$ & 2,183 &, 363 &, 137 \\
Pengurus Poktan $\left(\mathrm{X}_{6}\right)$ & $-5,291$ & 2,117 &, 012 &, 005 \\
Premi (D) & 5,004 & 2,068 &, 016 & 149,063 \\
Mekanisme Pelaksanaan $\left(\mathrm{D}_{2}\right)$ &, 334 & 5,805 &, 954 & 1,396 \\
Keyakinan Klaim (D) & & & \\
Constant & & & & \\
\hline
\end{tabular}

Sumber: Analisis Data Primer, 2020

Keterangan Signifikansi pada $\alpha=5 \%$

Tabel 4. Peluang Petani Mengikuti AUTP di Kabupaten Sukoharjo

\begin{tabular}{cc}
\hline Skenario & Peluang (\%) \\
\hline Skenario 1 & 32,42 \\
Skenario 2 & 0,32 \\
Skenario 3 & 98,96 \\
Skenario 4 & 38,99 \\
Skenario 5 & 6,18 \\
Skenario 6 & 0,04 \\
Skenario 7 & 92,89 \\
Skenario 8 & 8,07 \\
\hline
\end{tabular}

Sumber: Analisis Data Primer, 202 